\title{
'Tudo o que é sólido se desmancha no ar': os Parâmetros Curriculares Nacionais, suas contribuições e suas inconsistências às práticas de ensino de história
}

\author{
'All that is solid melts into air": the national curricular parameters, its contributions and its \\ inconsistencies on practices of teaching history
}

'Tout ce qui est solide se dissout dans l'air': les Paramètres Curriculaires Nationaux, leurs contributions et leurs incohérences dans les pratiques d'enseignement de l'histoire

José Petrúcio de Farias Junior ${ }^{1}$

Universidade Federal do Piauí

Resumo: Nossa proposta consiste em apresentar as principais diretrizes pedagógicas dos Parâmetros Curriculares Nacionais para o ensino fundamental e médio, tendo em vista sua estrutura organizacional. Destacamos, particularmente, os limites e possibilidades de tal documento para a renovação do ensino de História com a finalidade não só de contribuir para o aprofundamento teórico-metodológico das práticas de ensino na educação básica, mas também fomentar políticas públicas endereçadas à constituição de propostas curriculares municipais ou estaduais, sem desconsiderar esforços anteriores.

Palavras-chave: Parâmetros Curriculares Nacionais. Ensino de História. Currículo.

Abstract: Our proposal consists in presenting the main pedagogical guidelines of the Brazilian Curricular Parameters for elementary and secondary education, considering its organizational structure. We highlight, in particular, the limits and possibilities of such document for the renewal of History teaching with the purpose not only of contributing to the theoretical-methodological deepening of teaching practices in basic education, but also to foment public policies addressed to the constitution of municipal or state curricular proposals, without disregarding previous efforts.

Keywords. National Curriculum Parameters. Teaching of history. Curriculum.

Résumé: Notre proposition consiste à présenter les principales directives des Paramètres Curriculaires Brésiliens pour l'enseignement obligatoire et secondaire, en raison de leur structure organisationnelle. Nous mettons particulièrement en avant les limites et les possibilités de ce document pour rénover l'enseignement de l'Histoire afin de non seulement contribuer à l'approfondissement théorico-méthodologique des pratiques d'enseignement primaire, mais encore de promouvoir des politiques publiques visant à constituer des propositions curriculaires au niveau des municipalités ou des états, tout en tenant compte des efforts antérieurs.

Mots-clés: Paramètres Curriculaires Nationaux. Enseignement de l'Histoire. Curriculum.

\footnotetext{
${ }_{1}$ Professor Adjunto I da Universidade Federal do Piauí. Doutor em História e Pós-Doutor em Educação Coordenador Financeiro DINTER/UFU/UFPI. Coordenador dos Grupos de Pesquisas: Laboratório de História Antiga e Medieval História e Culturas Religiosas. E-mail: petruciojr@terra.com.br
} 


\section{Introdução}

Nossa proposta consiste em apresentar as principais diretrizes pedagógicas dos Parâmetros Curriculares Nacionais para o ensino fundamental e médio, tendo em vista sua estrutura organizacional. Destacamos, particularmente, os limites e possibilidade de tal documento para a renovação do ensino de História com a finalidade não só de contribuir para o aprofundamento teórico-metodológico das práticas de ensino na educação básica, mas também fomentar políticas públicas endereçadas à constituição de propostas curriculares municipais ou estaduais, sem desconsiderar esforços anteriores.

\section{Parâmetros Curriculares Nacionais para o ensino fundamental: chaves de leitura}

Publicados em 1998 pelo Ministério da Educação e pela Secretaria de Educação Fundamental, os Parâmetros Curriculares Nacionais passam por um longo processo de reformulação durante a década de 1990 até serem definitivamente aprovados. Nestes PCNs há uma composição de dez volumes: um introdutório, oito referentes a cada área de conhecimento, dentre elas História, e um volume que trata dos temas transversais. Em tese, eles derivam de princípios presentes no texto constitucional de 1988, mais precisamente nos artigos 205 e $210^{2}$, e objetivam oferecer orientações à educação escolar. Tais orientações adotaram como eixo vertebrador a concepção de cidadania já presente na Constituição, a qual é norteada por quatro princípios: primeiro, o princípio da dignidade da pessoa humana o que implica aversão a qualquer tipo de discriminação e pressupõe, por extensão, respeito mútuo nas relações interpessoais bem como acesso a condições de vida digna.

Segundo, igualdade de direitos, indispensável para assegurar a todos a mesma dignidade e possibilidade de exercício da cidadania; terceiro, participação, princípio que traz consigo a noção de cidadania ativa e, por fim, a co-responsabilidade pela vida social, que versa

\footnotetext{
${ }^{2}$ Constituição Federal de 1988, Artigo 205: “ A educação, direito de todos e dever do estado e da família, será promovida e incentivada com a colaboração da sociedade, visando ao pleno desenvolvimento da pessoa, seu preparo para o exercício da cidadania e sua qualificação para o trabalho”; Artigo 210: “ Serão fixados conteúdos mínimos para o ensino fundamental, de maneira a assegurar formação básica comum e respeito aos valores culturais e artísticos, nacionais e regionais”.
} 
sobre a responsabilidade pelos destinos da vida coletiva, os quais dependem, em grande medida, dos responsáveis pelos poderes públicos (PCNs, 1998, p. 21).

A ênfase direcionada às questões concernentes à cidadania como a dignidade humana se explica em razão da trajetória histórica da sociedade brasileira, marcada por traços de autoritarismo e corporativismo (escravidão; relações políticas paternalistas e clientelistas; governos pouco democráticos) e por traços de negligência aos direitos elementares dos cidadãos, tudo isso associado aos altos índices de desigualdade social, injustiça e exclusão social que ainda estigmatizam a sociedade brasileira.

Valorizar noções de cidadania e dignidade humana na educação básica é uma forma de conceber a escola como espaço de socialização de informações para que também se torne um espaço de transformação, desde que temas atinentes à realidade social sejam pensados de maneira colaborativa e interativa. Trata-se, em outras palavras, de um projeto de educação comprometido com o desenvolvimento de capacidades que permitam intervir na realidade para transformá-la (PCNs, 1998, p.24).

O estudo das principais dificuldades encontradas em diferentes regiões brasileiras, as quais representam um entrave à consolidação dos princípios constitucionais acima referenciados, foi organizado em um conjunto de seis temas que receberam o título de Temas Transversais, a saber: Ética, Meio Ambiente, Pluralidade Cultural, Saúde, Orientação Sexual, Trabalho e Consumo. Dessa forma, por se reportarem a questões sociais, os chamados Temas Transversais apresentam uma constituição diferente dos componentes curriculares obrigatórios, já que se referem a processos que estão sendo intensamente vivenciados pela sociedade, ou seja, é parte integrante de nosso cotidiano. Por essa razão, para elencá-los foram adotados os seguintes critérios:

\footnotetext{
1. Urgência social

2. Abrangência nacional

3. Possibilidade de ensino e aprendizagem no ensino fundamental

4. Favorecer a compreensão da realidade e a participação social. (PCNs, 1998, p. 25$6)$
}

A complexidade de tais temas não permite que sejam abordados por um componente curricular específico sem que haja diálogo com as outras áreas do saber escolar. Além disso, recomenda-se que tais temas sejam trabalhados periodicamente e que estejam integrados aos conteúdos disciplinares, por isso se chamam transversais: esses temas perpassam as disciplinas curriculares e se integram aos conteúdos básicos na medida em que o docente, em sua metodologia de ensino, adota a perspectiva de tais temas. 
No que tange à Ética, por exemplo, o docente pode, por meio de fragmentos ou textos completos da mitologia grega, estimular o aluno a pensar sobre a conduta humana, por exemplo, na opção ética de Páris: o que vale mais, o poder, o amor ou a inteligência? Ou o dilema ético de Aquiles: uma vida longa e medíocre ou uma vida curta e gloriosa? Convém advertir que essa prática de ensino deve se converter em atividades empregadas no âmbito da reflexão individual e coletiva. Como nos explica Ulisses F. Araújo, a educação ética e moral deve ajudar na análise crítica da realidade cotidiana e das normas sociomorais vigentes, de modo que contribua para idealizar formas mais justas e adequadas de convivência (2007, p. 13). O estudioso adiciona outros referenciais didáticos para elaboração de situações de aprendizagem que contemplam temas éticos e morais:

\begin{abstract}
Mas como os valores são apropriados pelos sujeitos? Adotamos a premissa de que os valores não são nem ensinados, nem nascem com as pessoas. Eles são construídos na experiência significativa que as pessoas estabelecem com o mundo. Essa construção depende diretamente da ação do sujeito, dos valores implícitos nos conteúdos com que interage no diaa-dia e da qualidade das relações interpessoais entre sujeito e a fonte dos valores. (ARAÚJO, 2007, p. 12-3)
\end{abstract}

No que diz respeito ao tema Pluralidade Cultural, os PCNs sugerem que o professor de História valorize as especificidades culturais de povos e civilizações distintas e demonstre de que maneira essas contribuições individuais enriquecem o patrimônio da humanidade. Nesse sentido, combater perspectivas etnocêntricas, geradoras de estereótipos, torna-se a tônica da prática de ensino de História. É muito comum, por exemplo, identificar em livros didáticos uma série de jogos binários, tais como: cristãos versus pagãos; civilizados versus primitivos; progresso versus atraso; romanos versus bárbaros. Muitos destes manuais reproduzem o ponto de vista dos romanos sobre os não-romanos, identificados genericamente pelo termo 'bárbaro’ e caracterizados como traidores, saqueadores, iletrados, incultos, inferiores e objeto de repúdio pelos romanos.

É preciso lembrar que essa é a visão da historiografia greco-romana sobre os chamados 'bárbaros' ou grupos étnicos não-romanos, visão que prevaleceu e tornou-se predominante, já que os chamados bárbaros permaneceram até meados do IV século de nossa era sem registros que pudessem relativizar os estereótipos veiculados pelos romanos por meio da literatura. Há também outros estereótipos: o árabe, visto em geral como "ignorante e fanático", judeu, "explorador"; o indiano, "sujo e primitivo", entre outros a serem combatidos e historicizados pelo professor. Diante disso, convém que se estimule a questionar as 
representações culturais estereotipadas, ou seja, construídas por um grupo social em relação ao outro.

Ainda no que diz respeito à imagem do bárbaro construída pelos romanos, o historiador François Hartog (1999) comenta que a construção da imagem do 'outro' apoia-se naquilo que é consensual na literatura latina acerca do que significa 'ser romano'. Para o estudioso é por intermédio de um jogo de espelhos que o 'outro' é caracterizado ou concebido. Ou seja, o romano reproduz a imagem do 'outro' ( os bárbaros) pelo prisma da diferença relativa ao 'ser romano', o que possibilita uma compreensão de si também ancorada em posicionamentos relativizados.

Dito de outro modo, pensamos que a imagem do bárbaro, na literatura latina, contribui para edificação da imagem do romano como povo "civilizado", portanto "superior" aos outros grupos étnicos. Os livros didáticos em geral fazem uma leitura literal das fontes e perdem a oportunidade de questionar tais registros a partir das marcas de autoria e destinatário.

Além disso, quando se aborda os bárbaros, ou até mesmo os romanos, os manuais de ensino em geral contentam-se em estabelecer as diferenças culturais de tais grupos de tal forma que a identidade desses grupos étnicos é apresentada de maneira homogênea, desconhecem-se as trocas culturais entre eles e as transformações decorrentes de diálogos culturais que contribuem para a fluidez de suas identidades culturais (CANEN, 2000, p.144).

O caráter reducionista com que os temas que versam sobre a pluralidade cultural são abordados derivam da orientação proveniente dos próprios PCNs. A título de ilustração, no interior do tema Direitos Humanos, Direitos de Cidadania e Pluralidade, proposto pelos PCNs, sugere-se a transversalização no tratamento da vida nas aldeias indígenas, ou dos processos de chegada e integração dos imigrantes em território nacional (...) (BRASIL, 1997, p.38). Embora o documento sinalize a importância de ressaltar a pluralidade de etnias indígenas, cada uma com identidade própria e representando riquíssima diversidade sociocultural (BRASIL, 1997, p. 06) e haja a inclinação em descrever as características sócio-culturais dos diferentes povos que imigraram para o Brasil, percebe-se que o tratamento do tema limita-se à descrição de formas de vida desses grupos, os quais são concebidos como categorias homogêneas (“indígenas", "imigrantes", "africanos").

Com isso, percebe-se que a maioria dos livros didáticos aprovados pelo PNLD desconsideram a construção de identidades híbridas e em constante processo de modificação na dimensão tempo-espaço. Como assevera Canen, os manuais buscam explanar sobre a 
organização familiar, os ritos, a vida comunitária, as linguagens empregadas, as expressões artísticas, enfim, visões "exóticas" e folclóricas da diversidade cultural, que reduzem a aspectos tais como rituais, receitas e costumes de povos diversos (2000, p. 136-7).

Esse viés interpretativo, sugerido pelos PCNs e reproduzidos na abordagem dos conteúdos históricos nos livros didáticos, colabora, no limite, para que os estudantes enxerguem a diversidade cultural como algo que está lá e não aqui. Em outras palavras, valoriza-se uma espécie de educação multicultural, divulgadora de diversas culturas, de paradigmas culturais plurais com a finalidade de fomentar o respeito mútuo, mas não contribui para compreensão do cidadão plural, multifacetado e em constante processo de transformação.

Da mesma maneira a concepção de identidade nacional, defendida pelos PCNs, desvaloriza a pluralidade identitária, em termos de gênero, raça, visões de mundo e a impossibilidade de se obter o senso de uma identidade nacional, ainda que haja indícios comuns entre os cidadãos brasileiros, como a língua, a moeda e o compartilhamento de símbolos que particularizam a nação.

Além disso, destacamos que a defesa da construção de uma identidade nacional se constrói à custa da subordinação de inúmeras identidades étnicas, religiosas, raciais, de gênero, de padrões culturais, entre outras. Com as palavras de Canen, marcadores de gênero, raça, preferências sexuais e padrões culturais e outros sobrepõem-se, em grande parte dos casos, à noção de identidade nacional, essa compreendida como "construção" e não como condição natural da formação identitária (2000, p. 140).

Dessa forma, ainda que os PCNs especificamente na introdução e na justificativa ao tema, contemplem satisfatoriamente a perspectiva da pluralidade cultural, para a pesquisadora Canen (2000, p. 146), tal abordagem não se sustenta no momento em que se analisa o documento mais detidamente. Para ela, predomina-se apenas um discurso de educação multicultural enviesado para aceitação de grupos sócio-políticos distintos. Trata-se de uma visão de pluralidade cultural que ignora a dinamicidade e a hibridização de culturas bem como uma não problematização da identidade nacional, como resultado de um construto discursivo instável, visão que ainda se reproduz nos livros didáticos de História.

Em relação ao tema Meio Ambiente, o docente pode se referir ao constante esforço do homem em assegurar não só sua própria sobrevivência, mas também a sobrevivência dos agrupamentos humanos em que estão inseridos. A descoberta e desenvolvimento da agricultura e da pecuária, desde a Pré-História, o que possibilitou agrupamentos humanos 
maiores e a construção de canais de irrigação, explicam, ao menos em parte, a sobrevivência e permanência das primeiras grandes civilizações da Antiguidade: povos mesopotâmicos, egípcios, chineses, indianos, entre outros, já que a água é uma questão essencial ao homem.

Os temas relacionados à Orientação Sexual deverão considerar, no limite, o nível de amadurecimento dos alunos, aspectos da cultura local e a relação com os pais. Dado o exposto, o professor pode mostrar que a sexualidade foi vista de modo diverso ao longo da História. Pode-se abordar aqui a cultura grega do culto ao corpo e suas implicações sociais na Grécia Antiga e na contemporaneidade: afinal é o corpo desejável um dado da natureza ou um dado cultural?

O tema da Saúde, assim como os demais, apresenta uma gama enorme de possibilidades, no entanto sugerimos a construção de quadros comparativos entre as práticas de cura e o cuidado de si, em diferentes momentos históricos, principalmente, no que diz respeito à importância das dietas, da higiene, da boa alimentação e de tratamentos populares contra doenças.

Por fim, o tema Trabalho e Consumo pode ser trabalhado em estreita ligação com o tema Meio Ambiente, com a diferença de que o docente pode explorar com mais propriedade a historicidade da divisão do trabalho quanto ao gênero e quanto ao processo de hierarquização da sociedade.

Dado o exposto, ajustamo-nos às orientações previstas nos Parâmetros Curriculares Nacionais que preveem o trabalho com a proposta da transversalidade a partir de quatro pontos:

\footnotetext{
1 os temas não constituem novas áreas, pressupondo um tratamento integrado nas diferentes áreas;

2 (...) necessidade de a escola refletir e atuar conscientemente na educação de valores e atitudes em todas as áreas;

3 a perspectiva transversal aponta uma transformação da prática pedagógica, pois rompe o confinamento da atuação dos professores às atividades pedagogicamente formalizadas e amplia a responsabilidade com a formação dos alunos.

4. a inclusão dos temas implica a necessidade de um trabalho sistemático e contínuo no decorrer de toda a escolaridade, o que possibilitará um tratamento cada vez mais aprofundado das questões eleitas. (PCNs, 1998, p. 28-9)
}

Ainda que tenha a pretensão de ser "nacional", porquanto ambiciona construir referências nacionais comuns para estruturar o processo educativo em todas as regiões brasileiras, tais "parâmetros" buscam respeitar diversidades regionais, culturais, políticas existentes no país (PCNs, 1998, p.09). Isso quer dizer que os PCNs não desrespeitam a autonomia das 
escolas de gerenciar seus projetos pedagógicos de acordo com as necessidades regionais. Pelo contrário, as unidades escolares têm autonomia para elaborar seus próprios documentos, desde que haja certa sintonia com a proposta nacional dos PCNs. Adicionado a isso, lembramos que os PCNs devem orientar a análise e seleção dos materiais didáticos a serem utilizados nas escolas, isto é, os livros didáticos deveriam contemplar a proposta sugerida pelos PCNs, o que em geral não ocorre.

De acordo com os Parâmetros Curriculares Nacionais (1998), a aplicação dos temas transversais implica uma abordagem epistemológica interdisciplinar no ensino de História, pois não é possível empregar atividades pautadas na transversalidade levando em consideração as limitações de uma única área do saber escolar, ou seja, de uma disciplina rígida. Nesse sentido,

A interdisciplinaridade questiona a segmentação entre os diferentes campos de conhecimento produzida por uma abordagem que não leva em conta a interrelação e a influência entre eles - questiona a visão compartimentada (disciplinar) da realidade sobre a qual a escola, tal como é conhecida, historicamente se constituiu (PCNs, 1998, p. 30)

Essa relação mútua de solidariedade entre transversalidade e interdisciplinaridade pressupõe uma proposta curricular mais flexível e menos conteudista.

Com a finalidade de analisar o currículo escolar, baseamo-nos nas categorias apontadas por Giroux (1987), em que este pode ser segmentado em três dimensões, a saber: currículo formal, currículo real e o currículo oculto. Isso posto, entende-se por currículo formal as diretrizes apontadas pelo projeto político-pedagógico da unidade escolar; por currículo real, consideram-se as práticas de ensino efetivamente realizadas em sala de aula, isso inclui a utilização do livro didático e, finalmente, por currículo oculto, compreende-se a omissão em relação às problemáticas socioambientais, como desdobramentos de um recorte espaçotemporal, reproduzido pelo currículo formal. Tal como declara Silva e Fonseca (2010, p. 16), um currículo de História:

(...) é, sempre, produto de escolhas, visões, interpretações, concepções de alguém ou de algum grupo que, em determinados espaços e tempos, detém o poder de dizer e fazer. Os currículos de História - sejam aqueles produtos das políticas públicas ou da indústria editorial, sejam os currículos construídos pelos professores na experiência cotidiana em sala de aula expressam visões e escolhas, revelam tensões, conflitos, acordos, consensos, aproximações e distanciamentos (FONSECA \& SILVA, 2010, p. 17)

Sob essa ótica, a orientação legada pelos PCNs (1998) principalmente em relação ao caráter interdisciplinar do conhecimento histórico, o que já pressupõe a integração dos temas 
transversais aos conteúdos básicos da disciplina, sugere que o currículo real esteja articulado com aspectos da realidade inerentes à vida dos estudantes, estes abordados não de maneira reducionista ou maniqueísta, mas em sua dinâmica e complexidade. Além disso, como prerrogativa indispensável à formação do currículo real, deve-se inserir questões atinentes ao patrimônio cultural e, por extensão, à história local, transversalizando discussões socioambientais a fim de que os alunos sejam reconhecidos como agentes históricos e não como meros expectadores.

Trata-se de uma abordagem que valoriza o pertencimento dos estudantes no processo de construção do conhecimento histórico, o qual para Mourão (apud FERRARO JR, 2005, p. 252) revela-se como característica indispensável ao desenvolvimento da autonomia de pensamento dos alunos, uma vez que

(...) se é verdade que toda visão humana de mundo é estritamente uma visão cultural, de quais limites jamais poderemos escapar (seja ela mítica, ideológica, filosófica ou científica), também é certo que o padrão cultural é aberto e se transforma exatamente na práxis dos indivíduos-sujeitos interconectados, na relação entre os ecossistemas e as sociedades humanas (FERRARO JR, 2005, p. 252)

Como se observa a práxis - e acrescento aqui os conhecimentos prévios construídos a partir dela - tornam-se elementos constitutivos da prática pedagógica do docente sem o qual a História se constitui em uma disciplina distante da vida dos alunos e sem nexo com a sociedade em que estão inseridos. Barbosa ratifica esse posicionamento ao declarar que:

Não é por outro motivo que observamos (...) que, para a maior parte dos
estudantes brasileiros, o estudo de história carece de sentido e utilidade; não
se tem a visão de ciência e sim de uma matéria decorativa, estudo do
passado, que só exige (...) a prontidão em declinar nomes, datas e fatos. Não
é de se estranhar que assim seja, porque ocorre a enorme distância entre a
realidade vivenciada pela comunidade e o tratamento dado ao ensino de
História, já que o aluno se torna mero espectador de fatos, não necessitando
esforços no sentido de qualquer reflexão ou elaboração. (BARBOSA, 2006,
p. 58 )

Verifica-se, dito de outra forma, que os PCNs recomendam que o chamado currículo real, na disciplina de História, não se distancie da complexidade dos acontecimentos históricos nos quais os alunos estão inseridos. Prática que requer a construção do conhecimento de maneira colaborativa, reflexiva e interativa a fim de assegurar a autonomia de pensamento. Para isso, é fundamental que o docente oportunize situações de aprendizagem em que o discente se torne protagonista do processo de aprendizagem e, por 
extensão, agente no processo de aquisição e reelaboração de informações com as quais lida. Tal como indica a Proposta Curricular do Estado de São Paulo:

O conhecimento de natureza enciclopédica, sem significação prática, é substituído por conteúdos e atividades que possibilitam não só a interação do aluno com a sociedade, mas também o aumento do seu poder como cidadão, propiciando maior acesso às informações e melhores possibilidades de interpretação das informações nos contextos sociais em que são apresentadas. Com tal mudança, a experiência escolar transforma-se numa vivência que permite ao aluno compreender as diferentes linguagens e usálas como meios de organização da realidade (...) (PROPOSTA CURRICULAR DO ESTADO DE SÃO PAULO, 2008, p. 35)

Nesse sentido, no plano do currículo real, orientado a práticas docentes voltadas à articulação dos conteúdos com eventos do real, à abordagem de temas transversais e a questões atinentes ao patrimônio cultural da comunidade escolar, o professor de História é consciente de que não é possível ensinar toda a história da humanidade. Para cumprir a referida proposta pedagógica, é necessário que o docente faça recortes espaço-temporais sobre os conteúdos da disciplina escolar História, os quais abarca, nos dois últimos ciclos do ensino fundamental, História Geral e do Brasil.

Por meio da publicação da Lei de Diretrizes e Bases - LDB (1996) e dos Parâmetros Curriculares Nacionais - PCNs (1998), os docentes adquiriram mais autonomia quanto à seleção dos conteúdos e à estruturação das situações de aprendizagem, desde que as habilidades e competências previstas para cada etapa escolar sejam trabalhadas. Isso quer dizer que o recorte espaço-temporal fica sob a responsabilidade do educador que passa a ter liberdade de (re)pensar o seu currículo real.

\section{Os Parâmetros Curriculares Nacionais para o Ensino Médio: propostas e limitações}

No que tange especificamente ao Ensino Médio, os Parâmetros Curriculares Nacionais para o Ensino Médio - PCNEM, publicados em 1999. enfocam a retomada e a atualização da educação humanista, o que pressupõe princípios estéticos, políticos e éticos como fundamentais para a organização escolar e curricular tal como previsto nas Diretrizes Curriculares Nacionais para o Ensino Médio e pela Comissão Internacional sobre a educação para o século XXI da UNESCO, fundamentados no aprender a ser, a conviver, a fazer e a conhecer.

Os autores dos PCNs para o ensino médio partem do pressuposto de que vivemos em uma sociedade em constante transformação, fruto da globalização, e caracterizada como 
"sociedade do conhecimento" ou "sociedade tecnológica". Essa linha argumentativa justifica o “aprender a conhecer”, pois vislumbra uma educação permanente para todos, alicerçada não mais na quantidade de informações, mas na forma de lidar com elas. (MAGALHÃES, 2007, p.61).

Outra proposta apresentada versa sobre a maneira como organizaram as disciplinas do componente curricular, as quais se encontram agrupadas em quatro grandes áreas: Ciências da Natureza e suas Tecnologias (Física, Química, Biologia); Matemática; Linguagens, Códigos e suas Tecnologias (Língua Portuguesa, línguas estrangeiras modernas, Educação Física e Artes); Ciências Humanas e suas Tecnologias (História, Geografia, Sociologia e Filosofia).

Verifica-se que a associação entre ciências e técnicas, que resulta em tecnologia, pressupõe a integração das revoluções industriais e científicas com todas as dimensões práticas da vida, inclusive, em se tratando das Ciências Humanas e suas tecnologias, o exercício da cidadania e a reivindicação de direitos assegurados pelo Estado.

Espera-se que os jovens que concluem o ensino básico devem estar preparados para saber se expressar e se comunicar com as linguagens da ciência e fazer uso de seus conhecimentos para se posicionar diante de questões gerais de natureza científica e tecnológica bem como diante de problemas pessoais ou sociais. Observa-se, com base nisso, que essa proposta curricular supera a simples divisão disciplinar do saber.

Reorganizadas em grandes áreas, as disciplinas passam a ser concebidas como campos complementares e articulados de investigação e sistematização de conhecimentos.

Ainda que, dentro do rol de disciplinas que compõem a área denominada "Ciências Humanas e suas Tecnologias", haja objetos de estudo e métodos próprios de investigação, procedimentos e critérios particulares de análise, elas compõem um acervo cultural articulado (...) e reúnem linguagens essenciais, recursos e valores que se completam para uma atuação prática e crítica na vida contemporânea (PROPOSTA CURRICULAR DO ESTADO DE SÃO PAULO, 2008, p. 28). Mais adiante, os autores dessa Proposta Curricular defendem que:

(...) o conjunto dessas ciências contribui para uma formação que permita ao jovem estudante compreender as relações entre sociedades diferentes; analisar os inúmeros problemas da sociedade em que vive e as diversas formas de relação entre homem e natureza, refletindo sobre as inúmeras ações e contradições da sociedade em relação a si própria e ao ambiente (PC/SP, 2008, p.39). 
Esse documento, embora esteja em sintonia com a LDB e com a Diretrizes do CNE - Conselho Nacional de Educação, apresenta limitações quanto à aplicabilidade dos princípios elaborados pelos referidos instrumentos legais. Os PCNEM-1999 não destacam, por exemplo, o papel central da escola como o lugar da reflexão sobre a prática educativa. Houve, portanto, a necessidade de elaboração de um documento mais específico que, de fato, oferecesse diretrizes concretas acerca da seleção dos conteúdos e elaboração de situações de aprendizagem em consonância com as propostas da LDB e das Diretrizes Curriculares para o Ensino Médio.

Elaboraram-se, então, em 2002, os PCNs+, que propõe o trabalho docente a partir de conceitos-chave ou conceitos estruturadores da História, tais como tempo, sujeito histórico, trabalho, memória, poder, historicidade, cultura e cidadania.

Assim, o PCN, de 2002, de forma menos superficial do que a versão de 1999, preocupou-se em ajustar a proposta curricular a uma linguagem mais familiar aos professores acerca dos conceitos e eixos temáticos. Além disso, a opção por romper a lógica da organização disciplinar dos conhecimentos foi mais bem desenvolvida. É curioso observa ainda que, ao final de cada volume, dos PCNs há um item intitulado Formação profissional permanente aos professores, que se divide em: A escola como espaço de formação docente e $A s$ práticas do professor em permanente transformação. Para Magalhães, tais itens sinalizam a visão do MEC acerca das lacunas na formação dos professores: logo, o problema encontra-se no professor, cuja formação ainda não está adequada a uma prática de ensino fundamentada em competências e habilidades (2006, p. 63).

Adicionado ao problema de formação, a proposta vai de encontro às experiências formativas disseminadas nas universidades e nas escolas; gerações de professores formaramse pensando na especificidade do ensino de suas disciplinas e valorizam conteúdos, conceitos e formas de construção do conhecimento que são particulares às disciplinas que ministram, por isso a proposta de organização das disciplinas por áreas ainda é um desafio.

Dada a contribuição dos PCNEM+, convém que façamos alguns apontamentos sobre a relação entre os conceitos estruturadores da História e as competências específicas da disciplina a fim de que reflitamos acerca da das possíveis propostas de aplicação na educação básica.

No que diz respeito à concepção de História, destaca-se a inclinação de metodologias de ensino-aprendizagem orientadas à construção do conhecimento histórico como instrumento para que o aluno se aproprie de um olhar consciente em relação a si e à 
sociedade. Além disso, ciente do caráter provisório do conhecimento, o aluno terá a oportunidade de vivenciar a prática da pesquisa histórica, semelhante à metodologia empregada nas academias, quais sejam: problematização; delimitação do objeto; busca de informações; estudo da bibliografia; levantamento de fontes sem desconsiderar suas especificidades; percepção dos sujeitos históricos; estratégias de verificação de hipóteses; organização dos dados coletados; refinamento dos conceitos; proposta de explicação dos fenômenos estudados; elaboração da exposição e redação de textos.

Em relação ao rol de fontes históricas que podem estar a serviço da compreensão de um acontecimento histórico ou de processos históricos, o docente dispõe de documentos oficiais, texto de época e atuais, mapas, ilustrações, gravuras, imagens de heróis de quadrinhos, poemas, letras de música, literatura, manifestos, relatos de viajantes, panfletos, caricaturas, pinturas, fotos, rádio, televisão, depoimentos, entrevistas.

Diante de tais procedimentos, julgamos oportuno ressaltar que a proposta não é formar pequenos historiadores, mas mostrar que a construção do conhecimento não é algo pronto e acabado. Ao contrário, trata-se de uma fabricação do historiador, isto é, um construto pessoal, lingüístico e intertextual, logo contém limitações e não pode ser concebido como verdade absoluta. A sensação de que o texto histórico corresponde a uma "realidade" deriva de procedimentos discursivos e de instituições sociais, como a academia, que legitimam o documento e levam a sociedade a interpretar-se e a compreender-se por intermédio dessas interpretações (LE GOFF, 1996, p. 548).

Quanto à concepção de processos históricos, o docente precisa ter em mente que o passado humano não se constitui de um conjunto de ações isoladas, ao contrário, trata-se de comportamentos interligados que têm uma razão de ser, ainda que, muitas vezes, difíceis de serem percebidos. A explicação histórica passa a ser marcada tanto por permanências e regularidades das formações sociais quanto por mudanças e transformações que ocorrem no embate das ações humanas. De acordo com as Orientações Curriculares para o Ensino Médio (OCEM):

(...) A História, concebida como processo, intenta aprimorar o exercício da problematização da vida social como ponto de partida para a investigação produtiva e criativa, buscando identificar relações sociais de grupos locais, regionais, nacionais e de outros povos, perceber diferenças e semelhanças, conflitos/contradições, igualdades e desigualdades existentes nas sociedades, comparar problemáticas atuais e de outros momentos, posicionar-se de forma analítica e crítica diante do presente e buscar as relações possíveis com o passado (OCEM, 2006, p.73) 
Nesse sentido, os registros ou as evidências da luta dos agentes históricos são o ponto de partida para entendermos os processos históricos. No entanto, o sentido dos acontecimentos históricos é mais bem compreendidos quando migramos de suas dimensões micro para os processos históricos que, em certa medida, emprestam-lhes possibilidades explicativas.

No item historicidade dos conceitos, identificamos uma prática de ensino importante sobre o emprego de conceitos históricos. Sabemos que nosso pensamento só se consolida pela linguagem e é por meio dela que compreendemos e nos aproximamos de experiências humanas do passado e do presente, todavia devemos observar a diacronia dos conceitos, isto é, pensar os conceitos e suas modificações semânticas no transcorrer dos anos.

Por exemplo, o conceito de cidadania aplicado para compreender a organização política de Atenas, difere-se, em alguns aspectos, de outras polis e reveste de outro significado quando aplicado na contemporaneidade. Dessa forma, o conceito não pode ser concebido como identidade fixa.

Adverte-se, por meio dessas orientações, para a necessidade de evitar explicações históricas anacrônicas. $\mathrm{O}$ anacronismo consiste em levar para o passado razões, sentimentos e experiências do presente sem que faça considerações a respeito das especificidades das circunstâncias históricas do passado, principalmente em relação ao emprego de conceitos elaborados para determinada época. A estratégia de ensino mais adequada consiste em observar os registros do passado e seus conceitos e associá-los aos conceitos do presente a fim de que os discentes compreendam o próprio movimento de mudança e de preservação; em outras palavras, as continuidades e rupturas, por isso os conceitos devem ser rastreados no tempo.

A dimensão da temporalidade, quarto conceito estruturador mencionado, é uma das categorias centrais do conhecimento histórico. Ele desempenha a função de núcleo orientador e estruturador do pensamento e da ação humanos. Assim, compreendemos, com mais propriedade, os fenômenos sociais na duração temporal que permite, por sua vez, o exercício explicativo das periodizações. No entanto, algumas ressalvas fazem-se necessárias:

Sendo um produto cultural forjado pelas necessidades concretas das sociedades historicamente situadas, o tempo representa um conjunto complexo de vivências humanas. Por isso, a necessidade de relativizar as diferentes concepções de tempo e as periodizações propostas, e de situar os acontecimentos históricos nos seus respectivos tempos. É de ressaltar a importância das periodizações, dos calendários e das contagens dos tempos como foram sendo sistematicamente construídos para que o aluno elabore, de forma problematizada, seus próprios pontos de referência como marcos 
para as explicações de sua própria história de vida, assim como da história dos homens em geral (OCEM, 2006, p. 74)

O conceito de sujeitos históricos aponta para necessidade de perceber a complexidade das relações sociais, pautadas não só por relações de poder que intermedeiam os contatos interpessoais, mas também pelo lugar institucional ocupado pelos sujeitos históricos, o qual contribui para explicação, muitas vezes, dos modos de agir e pensar. Importa-nos destacar aqui a emergência de uma concepção de História não mais ancorada em fatores externos à ação dos sujeitos históricos, tais como o Estado, os sistemas econômicos como o capitalismo e socialismo ou estruturas político-econômicas, mas sim no embate das relações sociais no tempo.

Em relação ao trabalho, utiliza-se com uma concepção bastante abrangente que permeia os processos históricos, já que compreendido como um modo de sustentação e autopreservação do gênero humano, por isso esse conceito é fundamental para abordar as transformações impostas pelo homem à natureza e à sua própria formação sócio-cultural que são historicamente construídas. As Orientações Curriculares para o Ensino Médio sugerem que:

Entende-se o trabalho na sua diversidade social, econômica, política e cultural, pois o trabalho não se refere somente às formas de produzir formalmente e historicamente aceitas nas diversas sociedades históricas, tais como a escravidão, servidão e o trabalho assalariado, mas também ao trabalho relacionado à esfera doméstica, à prática comunitária, às manifestações artísticas e intelectuais, à participação nas instâncias de representação políticas, trabalhistas, comunitárias e religiosas. Estas diferentes formas de produzir e organizar a vida individual e coletiva intercambiam-se com diversas perspectivas ou abordagens. Dentre elas pode-se destacar as de gênero (a participação das mulheres e homens nas relações entre trabalho formal, informal e doméstico); de parentesco ou de comunidade (posição dos membros na hierarquia da família e da comunidade relacionados a sua ocupação profissional); de geração (as transformações históricas na relação entre o trabalho formalmente aceito em uma sociedade e o trabalho infantil, além do trabalho como formação educativa nas dimensões professor/aluno, mestre/aprendiz, entre outras); e de poder (tensões e conflitos entre os diferentes agentes sociais, profissionais e políticos) (OCEM, 2006, p. 76, grifo nosso)

Quanto à concepção de poder não podemos dissociá-la da questão dos conflitos sociais. Assim, pensa-se que todos os agrupamentos sociais, no transcorrer da História, sejam marcados por conflitos, entendido aqui, como manifestação, no limite, da relação de dois poderes ou de dois princípios ideológicos, defendidos com maior ou menor intensidade por pessoas ou grupos distintos. Trata-se de um fenômeno sócio-cultural, inerente ao convívio 
humano coletivo, que pode sinalizar a propensão em exceder as condições a que estamos submetidos para propor mudanças, as quais geralmente se ajustam à nossa visão de mundo ou perspectivas sobre a vida, tendo em vista interesses particulares ou coletivos bem como crenças e experiências.

Com base nos PCNEM (2002), a propensão a observar conflitos humanos não parte de mera curiosidade, aprendemos muito com eles. Os conflitos humanos, em particular, tratam implicitamente de relações de poder sob a ótica de indivíduos pertencentes a determinadas categorias sociais. Não se pode afirmar que o indivíduo reproduza as dissensões do grupo social ao qual pertence como se elas fossem homogêneas ou percebidas igualmente por diferentes atores sociais, de tal forma que os leitores ou expectadores pudessem se identificar ou não com eles, mas declarar que os conflitos ou disputas sociais nos apresentam caminhos a partir dos quais um indivíduo ou uma sociedade podem ser pensados, tendo em vista as noções de autoridade, poder e preferências culturais, inerentes a uma situação de conflito.

Sob essa perspectiva, o conflito social, e não o consenso, é a situação predominante ou permanente da vida social em uma sociedade democrática como a nossa, segundo a qual a representação normativa do poder é geralmente produto de coerções e as estruturas políticoadministrativas, por extensão, são determinadas pela hierarquia entre os grupos sociais que compõem determinada sociedade. Sob essa concepção, o conflito passa a ser o fio estruturador da sociedade e concebido não como aspecto negativo ou degenerativo das instituições político-administrativas, mas como fator de coesão social e fortalecimento do poder político.

No que tange ao conceito de cultura, também observamos uma ampliação conceitual significativa que se deve à aproximação da História com a Antropologia e a Filosofia, tal como se averigua a seguir:

Cultura não é apenas o conjunto das manifestações artísticas. É, também, constituída pelas formas de organização do trabalho, da casa, da família, do cotidiano das pessoas, dos ritos, religiões, festas. As diversidades étnicas, sexuais, religiosas, e de classes constroem representações que constituem as culturas e que se expressam em conflitos de interpretações e de posicionamentos na disputa por seu lugar no imaginário social (...) A cultura, que confere identidade aos grupos sociais, não pode ser considerada produto puro e estável. As culturas são híbridas e resultam da troca e de relações entre os grupos humanos. Dessa forma, podem impor padrões uns sobre os outros, ou também receber influências, constituindo processos de apropriação de significado e práticas 
que contém elementos de acomodação-resistência (OCEM, 1996, p. 77, grifo nosso)

Verifica-se a relação mútua entre as concepções de cultura, representação ${ }^{3}$ e identidade. Munido dessas orientações curriculares, compreende-se a cultura como um conjunto de significados partilhados e construídos pelos homens para explicar o mundo. A cultura seria, então, uma construção social que atribui sentido às experiências de uma determinada categoria social historicamente datada, localizada e com interesses (políticos) definidos. Em outras palavras, a noção de cultura pode ser concebida como a tradução da realidade através de formas simbólicas, conferindo sentido às palavras, às coisas e às ações, ou seja, ela colabora para construção de representações sobre o mundo, já que deriva de grupos ou categorias sociais distintas. De maneira geral, aplicadas ao território da História, essas representações sociais, enfatizam a interação entre indivíduo e sua época, posto que o sujeito se autorrepresenta na representação que faz do momento histórico em que vive, ou melhor, o sujeito imprime sua identidade naquilo que representa.

O conceito estruturador memória, como previsto pelos PCNEM (2002), tangencia uma série de questões que culminam no papel da memória na disciplina História. Inicialmente, entende-se por memória todas as possibilidades de arquivamento e preservação do passado, sem exclusões ou discriminações. Em relação aos processos de construção da memória social, Guimarães (2006, p.47) nos adverte para a observação do caráter tendencioso da construção das memórias sociais, porquanto muitas narrativas memoriais manipulam experiências do passado para satisfazer posicionamentos políticos no presente. Para Guimarães o que estava em jogo era a construção de uma adequada e indispensável política da lembrança como forma de subsidiar um novo projeto de identidade coletiva (2006, p.50). Depreende-se, a partir dessa assertiva, que as experiências do passado atuavam como condição de forjar as bases sólidas da sociedade do presente, em outros termos, o passado é domesticado segundo demandas e exigências do presente (GUIMARÃES, 2006, p.49). Essa abordagem implica perceber e criticar, junto aos discentes, as construções da memória histórica, ao partir da crítica dos "lugares de memória" socialmente construídos. Com isso, exercita-se o conhecimento autônomo e crítico.

Em consonância com o que propõe Guimarães (2006), entende-se que a memória é desencadeada de um lugar, e este se situa no presente. Dito de outra forma, a percepção,

\footnotetext{
${ }^{3}$ Entende-se por representação formas específicas ou modos particulares de compreender o mundo e de se comunicar com ele. Trata-se de uma espécie de moldura que cria tanto a realidade quanto o senso comum sob o olhar de um indivíduo ou grupo, por isso essas representações inserem-se em um sistema de crenças que se baseia em valores, tradições e imagens do mundo.
} 
desencadeadora da lembrança, insere a memória no presente (SEIXAS, 2002, p.62-3). Bergson, por exemplo, declara que o jogo percepção/memória desenrola-se no campo das escolhas interessadas, visto que toda memória opera escolhas e seleção. Nota-se que seu posicionamento valoriza aspectos da memória voluntária, responsável pela reconstrução engajada do passado, ou seja, para o estudioso, a memória é ativada visando, de alguma forma, ao controle do passado (apud SEIXAS, 2002, p.42). De acordo com as OCEM:

Evidencia-se, por exemplo, que os lugares da memória são criações da sociedade contemporânea para impor determinada memória, que a concepção de memória nacional ou identidade regional constitui formas de violência simbólica que silenciam e uniformizam a pluralidade de memórias associadas aos diversos grupos sociais. Por isso, a questão da memória ou da educação patrimonial associa-se à valorização da pluralidade cultural e ao questionamento da construção do patrimônio cultural pelos órgãos públicos, que, historicamente, vêm alijando a memória de grupos sociais (como os escravos e operários) daquilo que se concebe como memória nacional (1996, p. 78).

Adiciona-se que uma das funções da memória é atualizar as lembranças, agindo. $\mathrm{O}$ caráter atualizador da memória demarca a concepção de descontinuidade do passado, uma vez que considera o sentido móvel das palavras, que é ativado, reencontrado, retomado, recriado e reatualizado de múltiplas formas pelo sujeito histórico a partir das condições sociais que o cercam. Como se observa, essa perspectiva revela um passado plural, descontínuo, passível, a todo instante, de atualização.

Por fim, o conceito de cidadania, recente na historiografia, confere especial atenção à chamada cidadania participativa, isto é, focada nos direitos à diferença. Nesse sentido, a disciplina deve contribuir para alicerçar essa prática de cidadania, especialmente colocando em evidência a diversidade das culturas que integram a história dos povos e a construção de suas identidades. Com base nisso, o ensino de História pode salientar as experiências de participação dos indivíduos e dos grupos sociais na conquista de direitos sociais, humanos, civis e políticos, os quais não se caracterizam por uma aquisição gradativa e linear, mas marcadas por oscilações, ou seja, por perdas ou negligências de direitos em diferentes momentos históricos.

Sendo assim, a historicidade do conceito de cidadania torna-se objeto de estudo da História e seus desdobramentos em nossa sociedade ainda é uma questão polêmica que precisa ser questionada a fim de que a sociedade brasileira, reconhecida como democrática, possa aprimorar a qualidade de vida dos cidadãos. Com essas reflexões, os alunos 
reconhecem seu pertencimento a uma sociedade que precisa repensar constantemente sua prática política.

Como se observa, os Parâmetros Curriculares Nacionais não apresentam uma proposta curricular rígida ou fixa. São apenas diretrizes ou sugestões apoiadas em uma filosofia de ensino e princípios educacionais que passaram a nortear o sistema de ensino do país. A seleção do conteúdo e suas formas de apresentação são de competência do professor em conformidade com o projeto pedagógico da escola. Sob essa ótica, os Parâmetros auxiliam os professores a organizar seus currículos, de acordo com o perfil de alunos das escolas em que atuam, já que a elaboração dos currículos de História deve coadunar com as necessidades específicas de cada região, de cada comunidade e de cada escola e, principalmente desenvolver habilidades e competências que assegurem a continuação da aprendizagem após a educação básica, a fim de que prossigam seus estudos em cursos superiores ou ingressem no mercado de trabalho, dotados de competências básicas e fundamentais para a vida social.

Em geral as competências associam-se frequentemente à ideia de desenvolvimento de habilidades. Esses termos, no contexto das reformas educacionais da década de 90, assumiram um papel central nos discursos das propostas curriculares. Diante disso, quando se pensa no âmbito do currículo básico, identifica-se, como já mencionamos, que o foco deixou de ser os conteúdos disciplinares para valorizar e reforçar, em contrapartida, a resolução de problemas, o raciocínio lógico, a compreensão leitora, o domínio de procedimentos metodológicos (habilidades procedimentais), a valorização do comportamento colaborativo (habilidades atitudinais), entre outros. As atividades aplicadas pelos docentes representam a chave para o desenvolvimento da autonomia do aluno para continuar a adquirir novos conhecimentos, ainda que a escolarização básica tenha sido concluída. De acordo com Silva, só assim o discente pode enfrentar as novas demandas do mercado de trabalho, que exigem profissionais mais flexiveis com grande criatividade e facilidade para o trabalho em equipe (2006, p. 58).

A necessidade de "aprender a aprender”, uma das máximas do discurso educacional contemporâneo, em um mundo marcado por constantes inovações científicas e tecnológicas, pode ter contribuído para que a escola se conscientizasse de que, por mais conteúdos novos e atualizados que pudesse oferecer, jamais conseguiria uma sincronia entre a formação dos discentes e as necessidades do mercado de trabalho. Tudo leva a crer que, em razão disso, a principal atribuição da escola passou a ser o desenvolvimento de competências básicas para 
que os estudantes adquiram novos conhecimentos de maneira autônoma, o que sinaliza a capacidade de atualizar, reciclar ou renovar os conhecimentos já adquiridos, habilidade indispensável à atuação dos estudantes no mercado de trabalho em todos os setores.

As competências e habilidades podem tangenciar todas as disciplinas escolares. Por competência, entendem-se modos de ser, raciocinar e interagir que podem ser depreendidos das ações e das tomadas de decisão em contextos de problemas, tarefas ou atividades. Para Perrenoud (2005), competência é uma capacidade de agir eficazmente em determinado tipo de situação apoiada em conhecimentos, mas sem limitar-se a eles (PERRENOUD, 1999, p.7). Já as habilidades derivam das competências, pois exprimem um "saber-fazer".

Trata-se, como já abordamos, de uma maneira de não segmentar áreas do conhecimento que se aproximam no que diz respeito a seu objeto de reflexão, ainda que o ângulo a partir do qual serão analisados sejam diferentes. No entanto, essa concepção de currículo referenciado em competências tem seus críticos. Os artigos que compõem o livro $O$ enigma da competência em educação (2004), por Joaquim Dolz e Edmée Ollagnier, reconhecem que o currículo referido a competência tem a pretensão de promover os conhecimentos próprios de cada disciplina articuladamente às competências e habilidades dos alunos, isto é, uma abordagem curricular por competências requer trabalho coletivo, uso de procedimentos na elaboração de tarefas, atitudes de cooperação e respeito, entre as competências já referenciadas, todavia Dolz e Ollagnier (2004) defendem que, ao fim e ao cabo, essa proposta curricular, nas escolas públicas brasileiras, acaba por privilegiar o desempenho individual dos alunos por meio de avaliações, em grande parte dos casos, objetivas.

Outra crítica versa sobre o esvaziamento da importância do conteúdo. A análise e interpretação de um texto passam a ser mais relevante do que o domínio ou reflexão sobre os processos históricos que colaboraram para sua produção. O pesquisador Luis Fernando Cerri, ao examinar a questão dos saberes históricos nas provas do ENEM mostra que há um predomínio de questões em que os conteúdos históricos são meros recursos para se aferir o quanto o aluno é capaz de entender o que lê. Particularmente, sustentamos, como já consta nos instrumentos legais, um equilíbrio entre abordagem dos processos históricos (macro) para a leitura, por exemplo, de fontes históricas, imagens, gráficos, mapas, etc (micro) a fim de que os estudantes não deixem de reconhecer que as fontes históricas devem ser compreendidas como produto do tempo em que foram elaboradas. Adicionado a isso, alguns estudiosos declaram que a estruturação dos currículos a partir de competências e habilidades conduz os estudantes a um certo aprender a fazer muito relacionado ao mundo da produção. 


\section{Referências}

ARAÚJO, U. F; LODI, L. H. Ética, cidadania e educação. In: Ética e cidadania: construindo valores na escola e na sociedade. Brasília: Ministério da Educação, Secretaria de Educação Básica, 2007.

BARBOSA, V. Ensino de História local: redescobrindo sentidos. Saeculum - Revista de História, João Pessoa, PB, n.15, p. 57-85, 2006.

BRASIL. Secretaria de Educação Fundamental. Parâmetros Curriculares Nacionais. Brasília: $\mathrm{MEC} / \mathrm{SEF}, 1998$.

Secretaria de Educação Fundamental. Parâmetros Curriculares Nacionais: História. Brasília: MEC/SEF, 1998.

Parâmetros curriculares nacionais para o ensino médio PCN+ Orientações Educacionais Complementares aos Parâmetros Curriculares Nacionais - Ciências Humanas e suas Tecnologias. Brasília/D.F: MEC - Secretaria de Educação Média e Tecnológica (SEMTEC), 2002.

MEC. Guia de livros didáticos: PNLD 2011: História. Brasília, 2010.

CANEN, A. Educação multicultural, identidade nacional e pluralidade cultural: tensões e implicações curriculares. Cadernos de Pesquisa, n. 111, 2000.

CERRI, L. F. Saberes históricos diante da avaliação do ensino: notas sobre os conteúdos de história nas provas do Exame Nacional do Ensino Médio ENEM. Revista Brasileira de História, n.48, v. 24, 2005, p. $213-231$.

DOLZ, J. \& OLlGNiER, E. O enigma da competência em educação. Porto Alegre: Artmed, 2004.

FERRARO JR, L. A. (Org.) Encontros e caminhos: formação de educadores ambientais e coletivos educadores. Brasília: MMA, Diretoria de Educação Ambiental, 2005.

FONSECA, S. G. \& SILVA, M. A. Ensino de História hoje: errâncias, conquistas e perdas. Revista Brasileira de história. SP, v. 31, n. 60, p. 13-33, 2010.

LE GOFF, J. História e memória. Trad. Irene Ferreira, Bernardo Leitão e Suzana Ferreira Borges. 5 . ed. Campinas: Editora UNICAMP, 2006.

MAGALHÃES, M. S. Apontamentos para pensar o ensino de História hoje: reformas curriculares, ensino médio e formação do professor. Tempo, v.1 1, n. 2 1, 2007.

PERRENOUD, P. Construir competências desde a escola. Porto Alegre: ArtMed, 1999.

SÃO PAULO. Proposta Curricular do Estado de São Paulo: história. São Paulo, Secretaria Estadual de Educação. 2008. 
SEIXAS, J. A. Os campos (in)elásticos da memória: reflexões sobre a memória histórica. In: SEIXAS, J. A.; BRESCIANI, M. S. \& BREPOHL, M. (orgs.) Razão e paixão na política. Brasília: Ed. UNB, 2002, p. 59-77.

SILVA, V. R. Concepções de História e de ensino em manuais para o ensino médio brasileiros, argentinos e mexicanos. Tese (Doutorado em História) - FFLCH/USP, 2006. 